\title{
Evaluation of phylogenetic relationship among Ficus palmata forrsk. wild ecotypes from Azad Jammu and Kashmir using inter simple sequence repeats (ISSR)
}

Ghazala Javed*, Syed Abdul Majid, Rizwan Taj and Asia Bibi Department of Botany, University of Azad Jammu and Kashmir Muzaffarabad, 13100-Pakistan *Corresponding author's email: khanghazal484@gmail.com

\section{Citation}

Ghazala Javed, Syed Abdul Majid, Rizwan Taj and Asia Bibi. Evaluation of phylogenetic relationship among ficus palmata forrsk. wild ecotypes from Azad Jammu and Kashmir using inter simple sequence repeats (ISSR). Pure and Applied Biology. Vol. 6, Issue 1, pp328-336. http://dx.doi.org/10.19045/bspab.2017.60031

Received: 10/01/2017 $\quad$ Revised: 23/02/2017 $\quad$ Accepted: 26/02/2017 $\quad$ Online First: 28/02/2017

\section{Abstract}

Ficus palmata is a very potent medicinal and multipurpose plant which has gained global significance due to medicinal and multipurpose utility. It bears deep violet to black berries which are known to human beings from centuries for their effects on health. The plant is wildly distributed throughout Azad Jammu and Kashmir. The phylogenetic relationship among these natural Ficus palmata ecotypes from Azad Jammu and Kashmir is not established so for using reliable molecular markers. ISSR has been proved to be an effective tool for the determination of phylogenetic relationship among closely related species. To construct a population level genetic profile for investigation and exploitation of genetic diversity of Ficus palmata, 25 ecotypes of Ficus palmata in AJK were analyzed using ISSR (Inter simple sequence repeats) markers. Phylogenetic distance estimated revealed that the ecotypes expressed common heritage for their phylogenetic relationship with a considerable genetic diversity among them as well. Quite a few Ecotypes showed close relationship irrespective of their geographic distances and morphological attributes. The research evolved a significant outcome to start a breeding program from the evolution of Ficus palmata varieties for the mountain areas of Azad Kashmir.

Keywords: Ficus palmata; ISSR; Ecotypes; Genetic diversity

\section{Introduction}

The figs (Ficus palmata species, Moraceae) are among the biggest genera of angiosperms with more or less 750 types of trees, epiphytes and bushes in tropical and subtropical areas around the world. Frodin [1] positioned them as the twenty-first biggest class of seed plants. Ficus palmata is a standout amongst the most differing plant genera as to development propensity, with both deciduous and evergreen detached trees, little bushes, creepers, climbers, stranglers, rheophytes and lithophytes [2]. The Asian-Australasian locale has the wealthiest and most different fig greenery with more than 500 species. By 
examination, the extravagance of Ficus in Africa and the Neotropics is lower, with pretty nearly 110 and 130 species, separately. Generally a large portion of the Ficus palmata species are monoecious, and the rest are practically dioecious $[3,4]$.

Characterization and evaluation of genetic diversity is the first step in the conservation and utilization of indigenous medicinal plant species. Portrayal and assessment of hereditary differing qualities is the initial phase in the preservation and usage of indigenous therapeutic plant species. Additionally Estimation of hereditary assorted qualities is an essential for enhancing of any species or hereditary material. Molecular markers have been used keeping in mind the end goal to describe therapeutic plants and assessment hereditary differences inside and among restorative plants genotypes utilizing diverse PCR methods in light of atomic and/or mitochondrial genomes [5]. The hereditary assorted qualities in regular plant populaces were shockingly at abnormal state in 1970 s when isozyme examinations were made. This set off the environmental geneticists to contemplate the relationship between the levels of hereditary variety, natural and life history attributes of numerous plant species $[6,7]$. Different molecular markers have been utilized for DNA fingerprinting studies as a part of fig and additionally for germplasm portrayal and investigation of hereditary differences in populaces [8-14]. For genotype recognizable proof, submolecular markers offer various points of interest over customary choices taking into account morphological characteristics because these markers are steady and discernible in every single plant tissue, paying little heed to natural conditions and formative stage. The primary points of interest of molecular markers are the reinduced time needed for the hereditary investigation of people $[15,16]$ and the likelihood of assessment amid seed or seedling stages. Microsatellite markers or straightforward grouping rehashes license the refinement of individual heterozygotes from homozygotes, the distinguishing proof of different alleles present in populaces, and the creation of effectively interpretable results with high reproducibility [17]. Consequently, these markers are helpful and dependable devices for the hereditary distinguishing proof of individuals. Molecular markers offer a steady and solid option for hereditary distinguishing proof and portrayal of germplasm accumulations. Recently, microsatellite, also known as Simple Sequence Repeats (SSR), randomly amplified polymorphic DNA (RAPD), intersimple sequence repeat (ISSR), restriction length polymorphism (RFLP), and mitochondrial DNA RFLP markers have been used in fingerprinting, and assessing genetic diversity, structure and differentiation in fig collections [18-21]. Keeping in view the global importance of Ficus palmata and its presence in Azad Kashmir as wild forests in abundance this research was conducted to assess the hereditary differences among chosen Ficus palmata ecotypes utilizing molecular markers and to look at the morphological, biochemical and molecular assorted qualities to be utilized as quality pool for Ficus palmata change in Pakistan and to suggest and set up the most proper ecotypes for delicate inclines of Azad Jammu and Kashmir.

\section{Material and methods Molecular characterization}

The leaves of Ficus palmata Forssk were used in molecular studies.

\section{Plant material collection and storage}

Selected plant species were collected from different geographical regions of Azad Jammu and Kashmir including Muzaffarabad, Pallandri, Rawalakot and Kotli. These plants were collected during 
their flowering season. All plant species were morphologically identified and taxonomically authenticated while using the flora of Pakistan. The plant material was preserved in sealed zipper bags added with the silica gel (Fisher chemical L-12167) at $4^{\circ} \mathrm{Ctill}$ further use.

\section{Plant material processing}

The leaf material was gently excised from the plants using an already sterilized scissor followed by washing with $70 \%$ ethanol and distilled water. The plant material was allowed for drying. 0.4 grams of the leaf material was weighted for DNA extraction using CTAB (Cetyl trimethyl ammonium bromide) method with few modifications [22].

\section{Genomic DNA confirmation}

Genomic DNA of the test samples were assessed by gel electrophoresis. The DNA sample $(5 \mu \mathrm{L})$ was mixed with loading dye bromophenol blue $(2 \mu \mathrm{l})$ and was run on $1 \%$ agarose gel. Ethidium bromide was used to stain and visualize the gel by taking picture under UV light by Dolphin Doc Plus gel documentation system (Wealtec).

\section{Polymerase chain reaction}

PCR reactions were carried out by 05 ISSR primers. The primers UBC807, UBC810, UBC812, UBC 816, UBC817 were used. The amplification reaction mixture of $25 \mu 1$ for each sample contained $1 \mu \mathrm{l}$ of template, $1 \mu 1$ of primer, $10.5 \mu \mathrm{l}$ of nuclease free water and $12.5 \mu 1$ of Master Mix (MBI Fermentas). Different concentrations of annealing temperature were tested for amplification using gradient PCR and finally a standard method was applied.

\section{Primers dilution}

Primers were initially diluted according to prescription by e-Oligos. Concentration of primer used was 25 picomole per $\mu 1$.

\section{PCR product confirmation}

The successful PCR products were confirmed by using $1.5 \%$ agasrose gel, prepared in $0.5 \mathrm{X}$ TAE buffer. Loading dye along with PCR product was loaded in wells of agarose gel. The gel was stained in ethidium bromide and was visualized under UV light in gel documentation system (Wealtec Dolphin Doc plus). The confirmation of size of particular band was done by running $50 \mathrm{~kb}$ DNA ladder with PCR products.

\section{Primers data scoring}

Primers data was scored as presence or absence of bands for each sample separately and monomorphic and polymorphic bands were calculated. All the visible segments were counted for each primer and presence or absence of bands was calculated as (1) if present and (0) when absent for each sample.

\section{Statistical analyses}

Molecular data was analyzed by software NTSYS-pc and PAST. A dendrogram based on similarity index was constructed by using Numerical Taxonomy and Multivariate Analysis System by [23].

\section{Results and discussion \\ Isolation of genomic DNA}

Genomic DNA of twenty five ecotypes of Ficus palamata are collected from different areas of Azad Jammu and Kashmir was extracted by CTAB method [24] with some modifications (Figure 1). The quantity and quality of extracted DNA was checked by running it on $1.5 \%$ gel. Concentration of DNA was determined by spectrophotometer at $260 \mathrm{~nm}$. and the purity of genomic DNA was measured by absorbance at $280 \mathrm{~nm}$. 

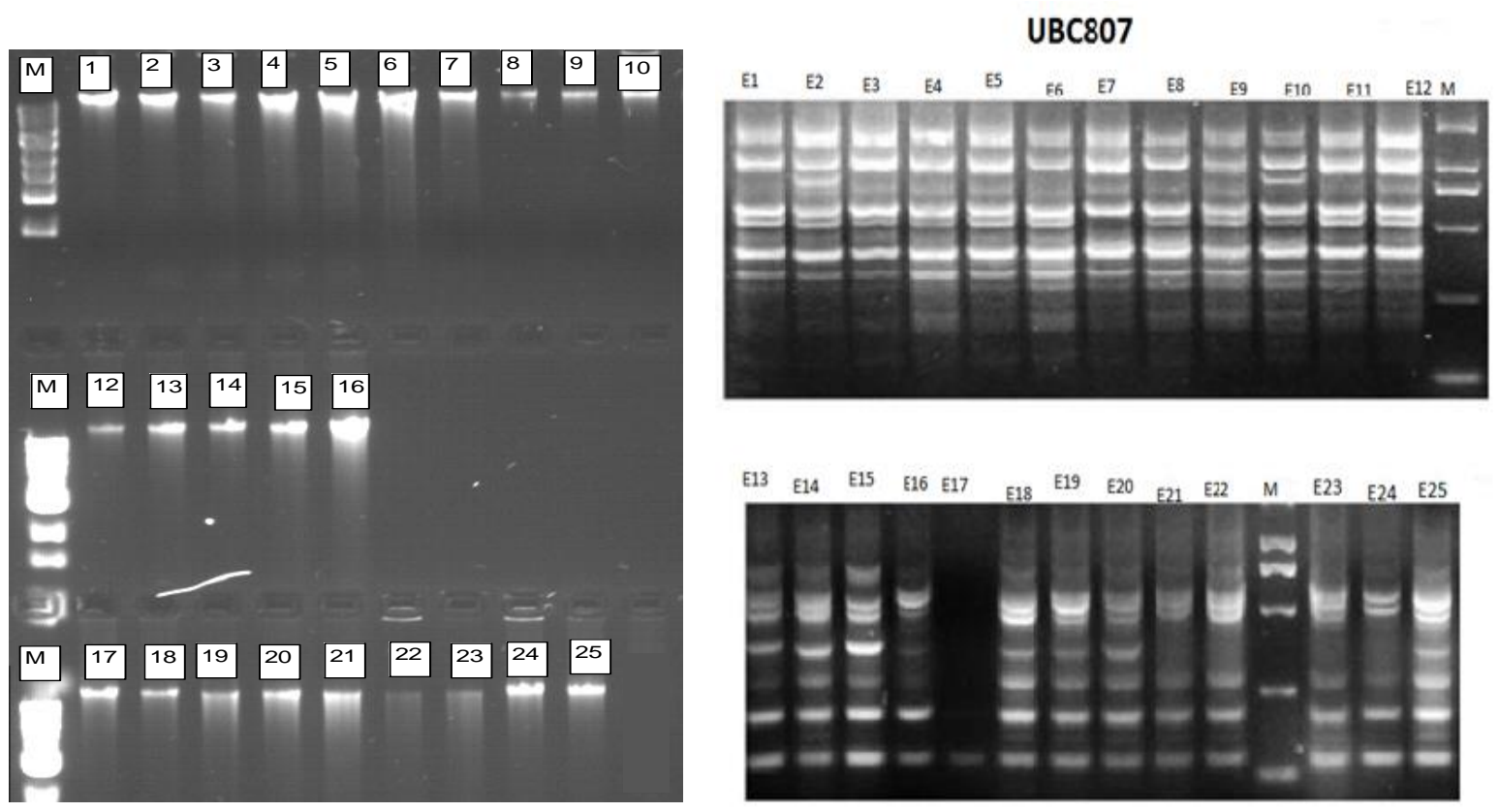

Figure 1. Genomic DNA extracted from 25 Ficus palmata ecotypes

\section{Optimization of PCR conditions}

Five ISSR primer were applied. All primers gave reproducible banding pattern .PCR reaction was performed using gradient PCR after optimizing different PCR conditions. Reaction mixture of 25 micro liter volume consist of 10.5 micro liter of nuclease free water , 12.5 micro liter of PCR master mix 1 micro liter primer and 1 micro liter of template DNA . It was found that annealing temperature for ISSR primers ranged between $51^{0} \mathrm{C}$ to $54^{0} \mathrm{C}$.

Confirmations of amplified products were done by running PCR products on $1.5 \%$ agarose gel. After gel electrophoresis the gel was stained in ethidium bromide buffer and band was observed under UV by using Dolphin Doc plus documentation system.

ISSR analysis of all the amplified products by 05 ISSR primers

A total of 29 bands were produced among the ecotypes of Ficus palmata grown in AJK in which 03 were monomorphic and 22 were polymorphic with a polymorphism of 76\% (Table 1) Molecular size of amplified fragments ranged from $50 \mathrm{bp}(\mathrm{UBC} 812)$ to 600bp (UBC810). The minimum number of DNA fragments was 05 while maximum number was 07bands . Moreover among all ecotypes only $10 \%$ monomorphism was found (Figure 2).

Table 1. Characteristics of ISSR banding profiles in 25 Ficus palmata ecotypes

\begin{tabular}{|l|l|l|l|l|l|l|}
\hline $\begin{array}{l}\text { Primer } \\
\text { code no. }\end{array}$ & Sequences & $\begin{array}{l}\text { Size range of } \\
\text { score able } \\
\text { bands (bp) }\end{array}$ & $\begin{array}{l}\text { Total } \\
\text { Bands }\end{array}$ & $\begin{array}{l}\text { No. of } \\
\text { monomorphic } \\
\text { bands }\end{array}$ & $\begin{array}{l}\text { No .of } \\
\text { polymorphic } \\
\text { bands }\end{array}$ & $\begin{array}{l}\text { Polymorphism } \\
\%\end{array}$ \\
\hline UBC807 & AGAGAGAGAGAGAGAGT & $100--450$ & 07 & 00 & 06 & $85 \%$ \\
\hline UBC810 & GAGAGAGAGAGAGAGAT & $300-600$ & 06 & 01 & 05 & $82 \%$ \\
\hline UBC812 & GAGAGAGAGAGAGAGAA & $50-500$ & 06 & 01 & 04 & $67 \%$ \\
\hline UBC816 & CACACACACACACACAT & $50-600$ & 05 & 00 & 04 & $80 \%$ \\
\hline UBC817 & CACACACACACACACAA & $100--400$ & 05 & 01 & 03 & $60 \%$ \\
\hline Total & & & 29 & 03 & 22 & $76 \%$ \\
\hline
\end{tabular}


UBC810

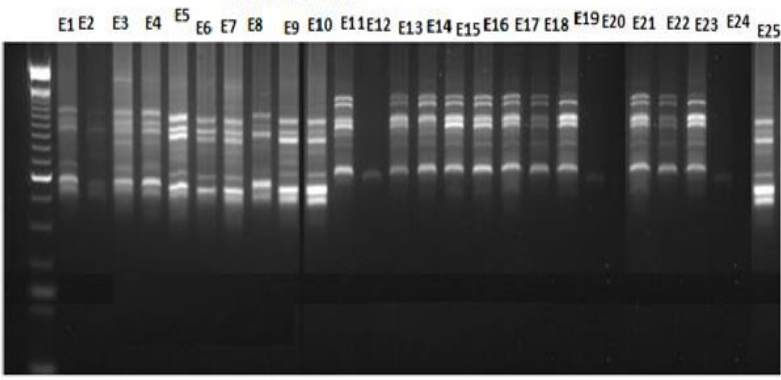

UBC812

$M$ E1 E2 E3 E4 ES E6E EY E9 E10E11E12E13E14E15E16E17E18E1
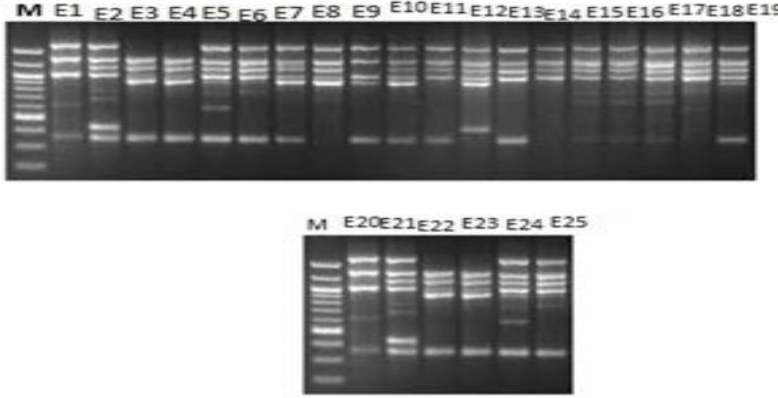

UBC816

M E1E2 E3 E4 E5E6 E7 E8E9 E10E11E12E13E14E15E16E1飞18E19E20 E21E22 E23E24 25

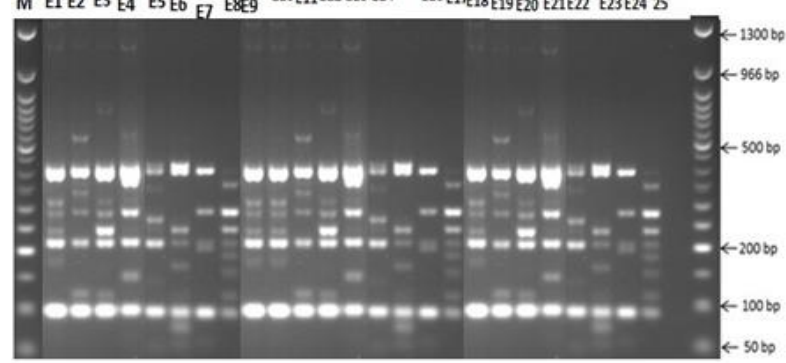

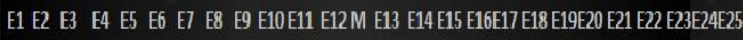

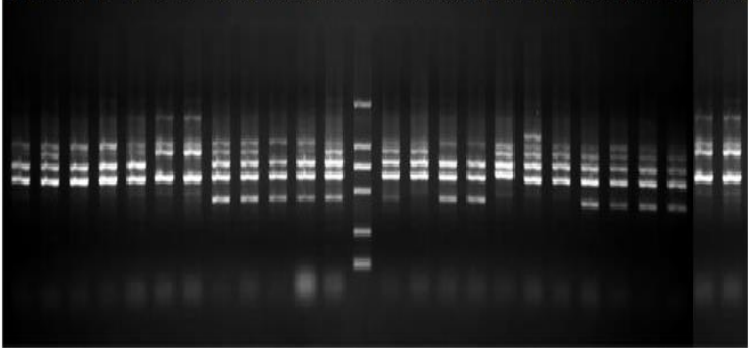

Figure 2. ISSR profile of 25 Ficus palmata ecotypes with primer UBC807, UBC810, UBC812, UBC816, UBC817

Cluster analysis of all the amplified fragments produced by 05 ISSR primers Dendrogram generated by NTSYS version 2.1e can be divided into two sub Clusters i.e. sub Cluster1a and sub Cluster 1b.All of the studied ecotypes of Ficus palmata have shown a similarity of $63 \%$ (Figure 3 ). It means $37 \%$ genetic diversity was found by using ISSR primers.

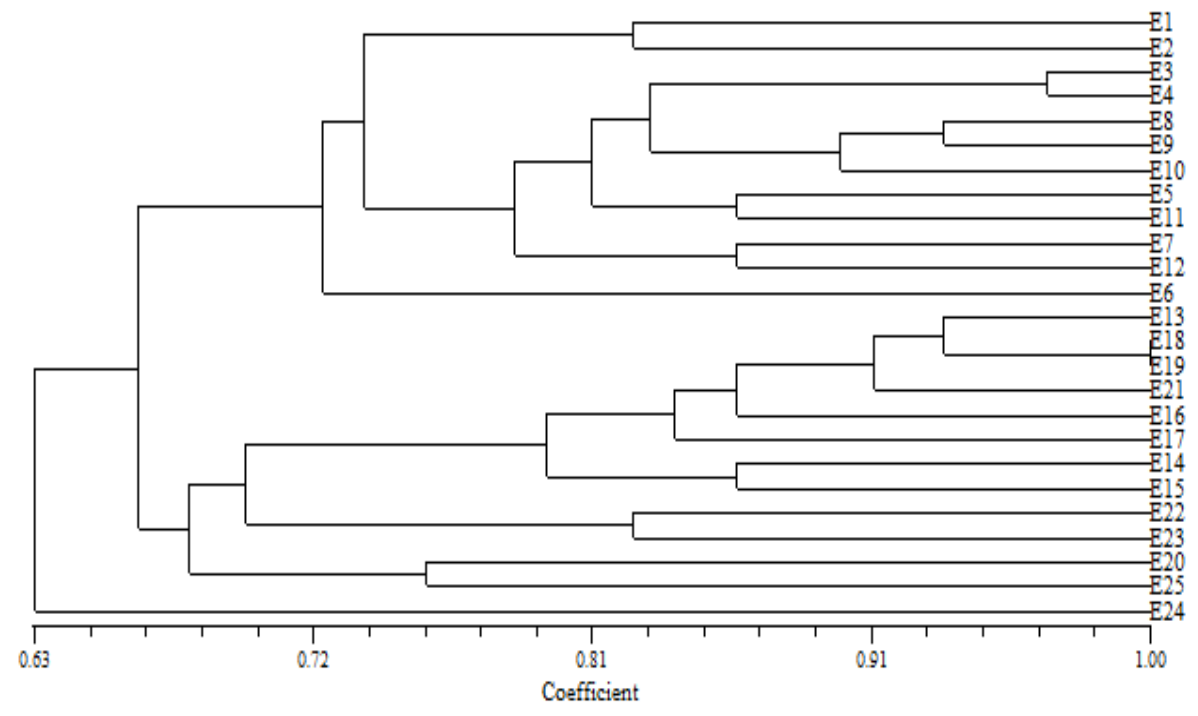

Figure 3. Dendrogram showing genetic relationship among 25 Ficus palmata ecotypes based on 05 ISSR primers 


\section{Sub Cluster 1a}

It consist of twelve ecotypes named as $\mathrm{E} 1, \mathrm{E} 2, \mathrm{E} 3, \mathrm{E} 4, \mathrm{E} 5, \mathrm{E} 8, \mathrm{E} 9, \mathrm{E} 10, \mathrm{E} 11, \mathrm{E} 7, \mathrm{E} 6$ and E12 .All these ecotypes shared a similarity of $72 \%$ to each other . No one Ecotypes shows $100 \%$ similarity to each other which means genetic diversity is present and these ecotypes shows genetic diversity to each other with some extent

\section{Sub Cluster 1b}

It consist of thirteen ecotypes namely E13, E18, E19, E21, E16, E17, E14, E15, E22, E23, E20, E25 and E24 showing an overall relatedness of $69 \%$ to each other. It means $28 \%$ genetic diversity was found in these ecotypes. The ecotypes within a group show close relation to each other while the ecotypes in different groups or different Cluster show more genetic diversity to each other.

Principal component analysis of ISSR primers (PCA)

PCA has shown that all studied Ficus palmata ecotypes can be divided into four groups (Figure 4). The ecotypes E11, E23, E22, E15 and E14 were located in the first group. While ecotypes E4, E3, E8, E9 and E5 gathered in second group. Similarly the third group comprises of E24, E25, E20, E16 and E10 while the fourth group consist of E2, E12, E7 and E6. It was observed that there is a close relationship between ecotypes of same group while genetic diversity was found among ecotypes of dissimilar groups. Hidetoshi et al. [25] worked on analysis of genetic diversity among Europeans and Asian Fig varieties using ISSR, RAPD, and SSR markers and concluded that each method is useful and informative for evaluating genetic diversity. Our result also agrees with Hidetoshi because all the SSR and ISSR primer are reliable and complementary for Ficus palmata characterization.

Khadari et al. [26] also proved the efficiency of these primers for Ficus characterization .Cluster and PCA analysis of combined data showed unique genetic structure in this population. These results suggested that the manners of polymorphism differ because of marker specificity. Little correlation between marker system was also reported in wheat [27] Soybeen [28] and Maize [29]. In addition the relation is assumed to depend on the genome coverage and sequence type recognized by each marker system and also explain by the fact that each marker represent only a part of the genome in the incongruence of the dendrogram.

The results also indicated that ISSR markers have been successfully utilized for assessing the genetic diversity and revealed a remarkable molecular discrimination between the Ficus palmata ecotypes under study. Moreover Galvan et al., [30] concluded that ISSR would be a better tool than RAPD for phylogenetic studies. Nagaoka and Ogihara. [31] have also reported that the ISSR primers produced several times more information than RAPD markers in wheat. The number of potential ISSR markers depends on the frequency of microsatellites, which changes with species [32], So that the Potential for integrating ISSR-PCR into plant improvement programme is enormous and their applications indifferent crop species are sufficiently reviewed [33]. 


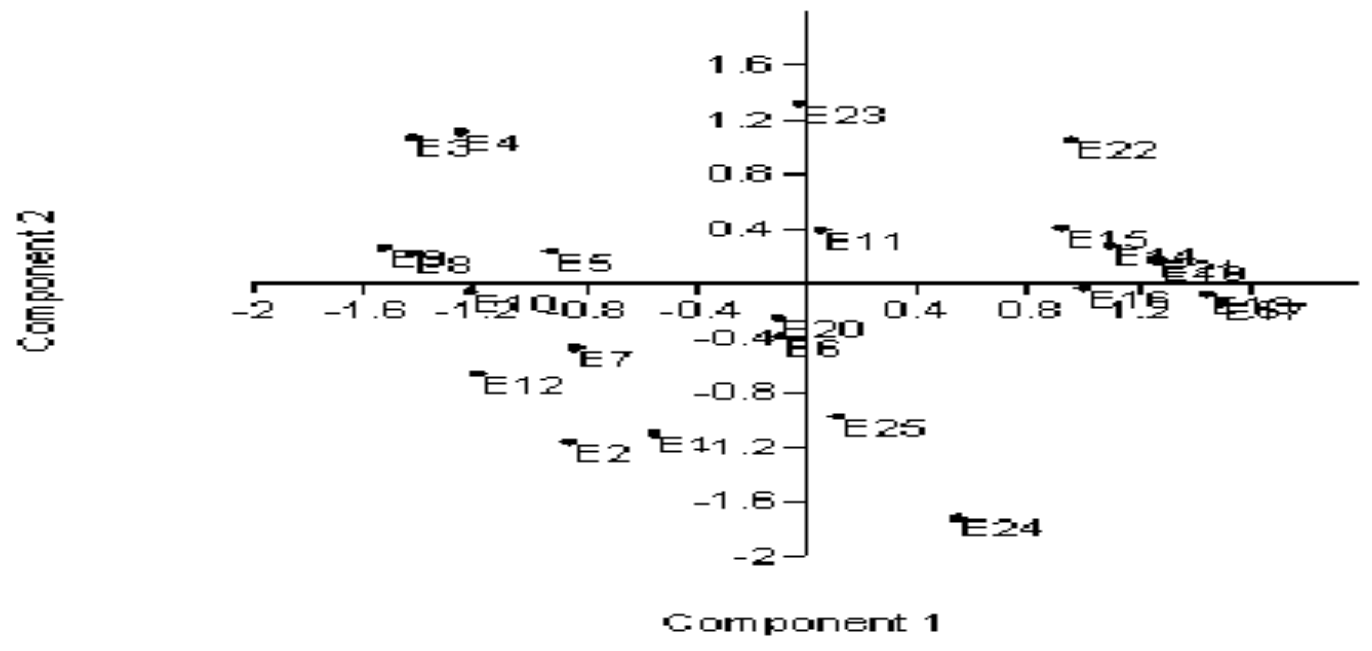

Figure 4. PCA of ISSR for 25 Ficus palmata ecotypes

\section{Conclusion}

The method described by [34] with some modifications proves to be more appropriate for the fast obtaining a good quality of DNA of Ficus palmta tree for the amplification by PCR. The utilization of microsatellites markers in order to study diversity of different cultivars of Ficus palmata revel the presence of 29 fragments. This study provides evidence that the ISSR procedure is an informative and suitable approach to the examination of the molecular polymorphism and the phylogenic relationships in the Ficus palmata germplasm. The overall results of this investigation demonstrated that all ecotypes studied could provide valuable material for use in breeding programs. Finally more works are necessary to enlarge the number of markers by the use of other molecular technologies in order to have a deeper insight into the molecular polymorphisms and to establish a varietal identification key in this plant.

Authors' contributions

Conceived and designed the experiments: $G$ Javed \& SA Majid, Performed the experiments: G JAved, Analyzed the data: G Javed \& SA Majid, Contributed reagents/ materials/ analysis tools: G Javed \& SA
Majid, Wrote the paper: G Javed, SA Majid, R Taj \& A Bibi.

\section{References}

1. Frodin GD (2004). History and Concepts of Big Plant Genera Taxon. Vol.53, No. 3: pp. 753-776

2. Harrison RD (2005). Figs and the diversity of tropical rainforests. Bioscience 55: 1053-1064.

3. Berg CC (2003). Flora Malesiana precursor for the treatment of Moraceae 1: The main subdivision of Ficus: The subgenera. Blumea 48: 167-178 http://dx.doi.org/10.3767/000651904X4 86278.

4. Berg CC \& Corner EJH (2005). Moraceae-Ficus. Pp.1-730. In: Nooteboom, H. P. (ed.), Flora Malesiana, Series I (Seed Plants), 17 (2): National Herbarium Nederland, University Leiden branch, The Netherlands 730pp.

5. Akbulut M, Ercisli $\mathrm{S} \&$ Karlidag $\mathrm{H}$ (2009). RAPD-based study of genetic variation and relationships among wild fig genotypes in Turkey. Genet Mol Res 8: 1109-1115.

6. Hamrick JL \& Godt MJV (1989). Allozyme diversity in plant species. Plant Population Genetics Breeding and 
Genetic Resources (eds Brown A.H.D, Clegg M.T., Kahler A.L. Weir, B.S) pp .33-63.

7. Hamrick JL \& Godt MJV (1996). Effects on history traits on genetic diversity in plant species. Philosophical transactions of the Royal Society of London, Series B 351: 1291-1298.

8. Khadari B, Oukabli A, Ater M \& Mamouni A (2004). Molecular characterization of Moroccan Fig germplasm using inters simple sequence repeat and simple sequence repeat markers to establish a reference collection. Hort Science 40: 29-32.

9. Akbulut M, Ercisli S \& Karlidag H (2009). RAPD-based study of genetic variation and relationships among wild fig genotypes in Turkey. Genet Mol Res 8: 1109-1115.

10. Ikegami $H$, Nogata $H$, Hirashima $K$ \& Awamura M (2009). Analysis of genetic diversity among European and Asian fig varieties (Ficus carica L.) using ISSR, RAPD, and SSR

11. Achtak H, Ater M, Oukabli A \& Santoni S (2010). Traditional agro-ecosystems as conservatories and incubators of cultivated plant varietal diversity: the case of fig (Ficus carica L.) in Morocco. BMC Plant Biol 10: 28-35.

12. Aradhya M K, Stover E, Velasco D \& Koehmstedt A (2010). Genetic structure and differentiation in cultivated fig (Ficus carica L.). Genetica 138: 681-694.

13. Chatti K, Baraket G, Ben AA \& Saddoud O (2010). Development of molecular tools for characterization and genetic diversity analysis in Tunisian fig (Ficus carica) cultivars.

14. Dalkiliç Z, Mestav HO, Günver-Dalkiliç G \& Kocatas H (2011). Genetic diversity of male Fig (Ficus carica L.) genotypes with random amplified polymorphic DNA (RAPD) markers. Afr J Biotechnol 10: 519-526.

15. Agarwal M, Shrivastava N \& Padh H (2008). Advances in molecular marker techniques and their applications in plant sciences. Plant Cell Rep 27: 617-631.

16. Gomes FA, Oliveira JG, Viana AP \& Siqueira APO (2010). RAPD molecular markers and morphological descriptors in the evaluation of genetic diversity of guava (Psidium guajava L.). Acta Sci Agron 32: 627-633.

17. Alba V, Montemurro C, Sabetta W \& Pasqualone A (2009). SSR-based identification key of cultivars of Olea europaea L. diffused in Southern Italy. Sci Hort 123: 11-16.

18. Khadari B, Hochu I, Santoni S \& Kjellberg F (2001).Identification and characterization of microsatellite loci in the common Fig (Ficus carica L.) and representative species of the genus Ficus. Mol Ecol Notes 1: 191-193.

19. Papdopoulou K, Ehaliotis C, Tourna M, Kastanis P, Karydis I \& Zervakis (2002).Genetic relatedness among dioecious Ficus carica L. cultivars by randomly amplified polymorphic DNA analysis, and evaluation of agronomic and morphological characters. Genetica 114:183-194.

20. Salhi-Hannachi A, Mokhtar T, Salwa Z, Jihene $\mathrm{H}$, Messaoud V, Abdel majid R \& Mohamed M (2004). Inter-simple sequence repeat fingerprints to assess genetic diversity in Tunisian fig (Ficus carica L.) germplasm. Genet Resour Crop Evol 51: 269-275.

21. Khadari B, Grout C, Santoni S \& Kjellberg F (2005). Contrasted genetic diversity and differentiation among Mediterranean populations of Ficus carica L.: a study using mt DNA RFLP. Genet Resour Crop Evol 52: 97-109. 
22. Richards EJ (1997). Preparation of plant DNA using CTAB. In: Ausubel F, Brent R, Kingston RE, Moore DD, Seidman JG, Smith JA, and Struhl K (eds), Short protocol in molecular Biology. Wiley 2: 10-211

23. Rohlf FJ (1997). NTYSYS-pc numerical taxonomy and multivariate analysis system, version 2.0. Exeter Publications, NY. Genetic Resources and Crop Evolution 54(6): 1315-1326.

24. Richards EJ (1997). Preparation of plant DNA using CTAB. In: Ausubel F, Brent R, Kingston RE, Moore DD, Seidman JG, Smith JA \& Struhl K (eds), Short protocol in molecular Biology. Wiley 2: 10-211

25. Hidetoshi I, Nogata H, Hirashima K, Awamura M \& Nakahara T (2008). Analysis of genetic diversity among European and Asian fig varieties (Ficus carica L.) using ISSR, RAPD and SSR markers. Gen Res Crop Evol 56: 201-209.

26. Khadari B, Hochu I, Santoni S, Oukabli A, Ater M, Roger JP \& Kjellberg F (2003). Which molecular markers are best suited to identify Fig cultivars: A comparison of RAPD, ISSR and microsatellite markers. Acta. Horticulturae 605: 6975.

27. Bohn M, Utz HF \& Melchinger AE (1999). Genetic similarities among winter wheat cultivars determined on the basis of RFLPs and SSRs and their use for predicting progeny variance. Crop Sci 39: 228-237.

28. Powell W, Morgante M , Andre C, Hanafey M , Vogel J , Tingey S \&
Rafalski A (1996). The comparison of RFLP, RAPD, AFLP and SSR (microsatellite) markers for germplasm analysis. Mol Breeding 2: 225-238.

29. Bohn M, Utz HF \& Melchinger AE (1999). Genetic similarities among winter wheat cultivars determined on the basis of RFLPs and SSRs and their use for predicting progeny variance. Crop Sci 39: 228-237

30. Galvan MZ, Bornet B, Balattiand PA \& Branchard M (2003). Inter simple sequence repeat (ISSR) marker as a tool for the assessment of both genetic diversity and gene pool origin in common bean (Phaseolus vulgaris L.). Euphytica 132(3): 297-301.

31. Nagaoka T \& Ogihara Y (1997). Applicability of inter simple sequence repeat polymorphisms in wheat for use as DNA markers in comparison to RFLP and RAPD markers.

32. Depeiger A, Goubely C, Lenoir A, Cocherel, Picard G, Rayanl M, Greltel $\mathrm{F}$ \& Delseny (1995).Identification of the most represented repeat motif in Arabidopsis thaliana microsatellite loci. Theor Appl Genet 91: 160-168.

33. Reddy MP, Sarla N \& Siddiq AE (2002).Inter simple sequence repeat (ISSR) polymorphism and its application in plant breeding. Euphytica 128: 9-17.

34. Richards EJ (1997). Preparation of plant DNA using CTAB. In: Ausubel F, Brent R, Kingston RE, Moore DD, Seidman JG, Smith JA, and Struhl K (eds), Short protocol in molecular Biology. Wiley 2: 10-211. 